\title{
How "Civic" the Trend Developed in the Histories of the Universities
}

\author{
Xianfeng Wu, Philip Oldfield \\ Department of Architecture and Built Environment, The University of Nottingham, Nottingham, UK \\ Email: laxxw16@nottingham.ac.uk
}

Received January 2015

\begin{abstract}
Historically, the definition of the University is inevitably dynamically changed by the theories, culture and social perspectives of different times. The university in the 21st century has an obvious tendency to much more flexible, integrated and most importantly, civic. This paper firstly clarifies the definition of the university; then the relationships between the university and the city are discussed. Thirdly, the civic university in U.K and U.S are separately reviewed. Lastly, the trend of the university-civic-is summarised and the future work on how to make high density university in 21 st century increasingly civic is proposed.
\end{abstract}

\section{Keywords}

\section{Civic, University, Higher Education}

\section{The Definition of the University}

There is no one specific definition of a university. As Denman [1] summarised: a university is a complex higher education organization that is formally authorised to offer and confer advance degrees in three or more academic disciplines or fields of study. However, this summarised conclusion cannot provide a precise definition of all universities' contents. It is hard to separate the definition of the university into several generations because the development of the university is dynamic and closely follows social progress. Because of this, the definition of the university evolved in a dynamic manner. From Athens Lyceum to Online Courses in Harvard University and MIT, the purpose of higher education keeps transforming, patterns of higher education changing and the function of university evolving. However, the story sounds like a novel which describes how the university developed step by step. Struggling and released from religious and aristocratic control, the university tends to be an autonomic and academically free place. In the globalisation and Information age, the university became an academic community intensively linked with the city it is located in or around. In the following chapters, civic universities are introduced to present how the university and the city link and demonstrate that the university is increasingly civic.

\section{The Relationship between the University and the City}

"Universities are ‘good' for cities and cities ‘good' for Universities.” 
—Van den Berg \& Russo (2003) [2]

The relationship between the university and the city is a multi-faceted one of distinct but interrelating physical, social, economic and cultural dimensions [3]. Simultaneously, Goddard and Vallance [3] purposed that the intersection and synergy of these institutional and academic roles creates opportunities for university to deepen social sustainable and public engagement (p. 90, 110).

University higher education provides "skilled workers" and talents to the city while university attracts national and international flows to increase recruits (Figure 1). What the city supports toward the university is not limited to economic funds and infrastructure facilities but also an urban environment to support studying communities. The urban theory of the Beaux-Arts tradition put great emphasis on city planning, and its principles of urbanism became the foundation of the "City Beautiful" movement in American in the late 1890s. It was therefore natural that many of the new American universities, large both in size and ambition and thinking of themselves as cities of learning, should turn to the newly fashionable Beaux-Arts system to create their physical form and self-image [4]. And in this process, the college in the Americans had to become even more fully a kind of miniature city [4].

In return, the beautified campuses and their facilities extremely attract citizens to get involved in, which made the city like a "superuniversity". When Joshua Lederberg was asked how it felt after many years in suburban California to return to the city of his youth in the interview of the New Yorker magazine's famous "Talk of the town' column in 1978, he expressed a mixture of nostalgia and insight into the nature of cities, universities, and creativity: ... New York is a superuniversity..." [5]. Bender [6] asserted that over the course of the past few centuries cities and universities have shared some key formal sociological characteristics: secularity, tolerance, specialisation, concentration, and diversity. Through retrospection of the history of the modern university in the United States, an impulse to withdrawal and an affinity with the purified, safe, and calm life of the suburbs-a dreamy city, to build the spirits and systems of the university campus. In that way, the urban universities are created rather than just a university built in a city.

\section{The Classical Civic University}

In this section civic universities in Great Britain and the civic universities in U.S are separately introduced. In the 19th century, six civic universities were established in industrial cities in Great Britain—Leeds, Birmingham, Bristol, Liverpool, Sheffield and Manchester. Professor Edgar Allison Peers first described the main building of the University of Liverpool with a distinctive red pressed brick in his 1943 book Redbrick University [7]. Hence, the "redbrick" term became a code for all the civic universities of the day. Through the term "red brick university" is much more well-known all over the world, the name "civic" presented manifest characters to obtain urban infrastructure facilities in the civic perspective.

Compared with the civic university in the Great Britain, the development of higher Education in American is divided into three generations [8]. The first generation began through a uniquely American adaptation of the

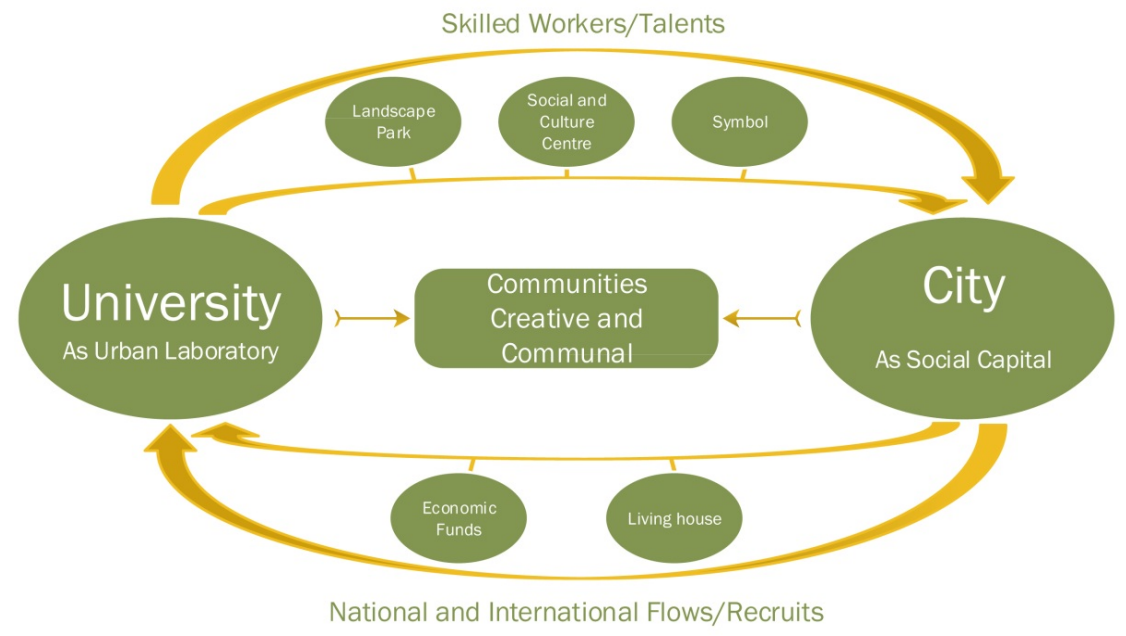

Figure 1. Relationship between the university and the city (Source from: Author). 
German education model, and then, American research universities found their own roles in the society [9]. The Second generation occurred in 1945. The information exploration age created Cold War Entrepreneurial University [10]. In general, it is believed that the third revolution began in 1989 with the emergence of the democratic cosmopolitan civic university. The main reason of this revolution is a reflective response to realistic contradictory conflictions between the powers of the university and the pathological state of cities [9]. The discussion and contraction on the values of a university towards a city, turned increasingly radical and troubling. Mutual respect and public collaboration with local communities can reduce or avoid worse situation. An establishment of the civic university can support emerging industries, contribution to public health, educate the workforce and provide debate about scientific and societal challenges. The third revolution of the civic university in the USA is still in its early stages.

From the view of Civic University in England and USA, we can clearly see that the definition of "civic" here is not simply using urban infrastructure facilities. In other word, the relationship between the University and the City and the civic educational conscious for lifelong learning are emphasised. The main mission of the university is to impart knowledge, explore research as well as humanise citizens. Professor John Goddard OBE from Newcastle University revealed the distinctions between the "un-civic" University and the civic University at the Centre for Urban \& Regional Development Studies conference (Figure 2).

Goddard suggests the un-civic university has a hard boundary between teaching, research and what he terms "third mission activities" which remain distinct [3]. However, the civic university provides direct engagement with society with research and teaching designed to provide socio-economic impact and to widen participation and provide community work. In urban sociology, universities have been defined alongside institutions such as museums and theatres as "auxiliary players" in city growth processes [3]. The soft boundary between the city and the university provides an intensive link to widening participation, community work and socio-economic impact. Increased public funding for research followed narrowly defined academic criteria and higher education was rolled out across the nation to fill in the map of teaching and learning with a diverse set of institutions. Now nearly all UK cities have one or more universities [11].

\section{Conclusion}

In the globalisation and Information age, the university became an academic community intensively linked with the city which is located in or around. Through the Civic University historical review in the United Kingdom and American, a brief history on how the University developed to be increasingly civic is introduced. More specifically, from a higher education policy perspective engagement with a city can provide an outward and visible sign of the university's contribution to civil society. But there are potential tensions here between internationally acknowledged academic excellence and societal accessibility to knowledge that urban engagement implies. The concept of the Civic University derived from the UK in the $19^{\text {th }}$ century in response to the challenges of rapid industrialisation and urbanisation. The responsibility of this kind of university is to do research supporting emerging industries, making a contribution to public health, disseminating knowledge that is beneficial for the workforce and providing a platform for debate about scientific and societal challenges. Base on above all,
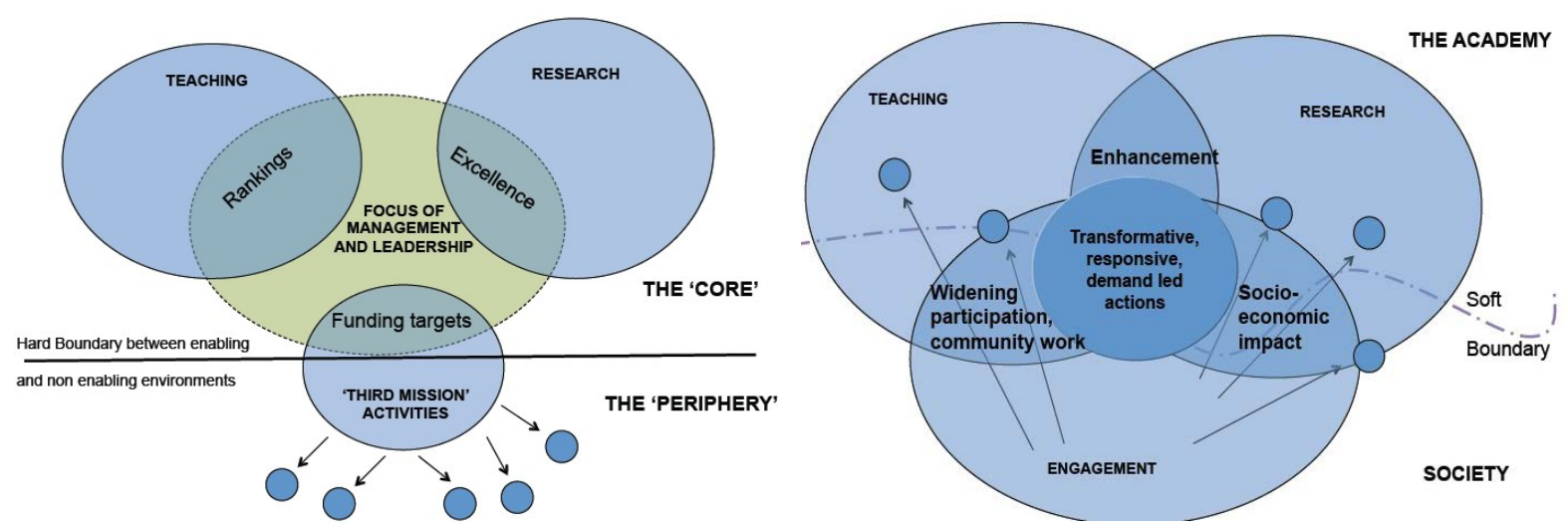

Figure 2. The Differences between the "un-civic” and “civic” university (Source from: a presentation of Prof. John goddard OBE in centre for urban \& regional Development Studies conference). 
increasingly civic is a main character of $21^{\text {st }}$ century’s University. The "civic” enhance the relationship between the city and the university.

\section{Future Work}

Many modern universities attempt to occupy the area of big cities and to be civic. In high density cities, like Hong Kong, New York and London, urban community colleges, with less area to build on, sometimes structured their buildings around vertical rather than horizontal social space [4]. Limited education areas are mainly to serve and support formal learning. How to allocate formal and informal learning spaces and establish the sense of community in these "vertical campuses" to fulfill the pivotal civic role is increasingly important in the $21^{\text {st }}$ century.

\section{References}

[1] Denman, B.D. (2005) What Is a University in the $21^{\text {st }}$ Century? Higher Education Management and Policy, 17, 9. https://www1.oecd.org/edu/imhe/42348396.pdf\#page=11

[2] Van den Berg, L. and Russo, A.P. (2003) The Student City: Strategic Planning for Student Communities in EU Cities. Proceedings of the ERSA Conference, European Regional Science Association, August 2003, 485.

[3] Goddard, J. and Vallance, P. (2013) The University and the City. Rouledge.

[4] Turner, P.V. (1986) Campus: An American Planning Tradition. Architectural History Foundation.

[5] Talk of the Town (1978) New Yorker, 13rd November.

[6] Bender, T. (1998) Scholarship, Local Life and the Necessity of Worldliness. In: Herman, V.D.W., Ed., The Urban University and Its Identity: Roots, Location, Roles, Springer, Netherlands, 17-28. http://dx.doi.org/10.1007/978-94-011-5184-9_2

[7] Mackenzie, A.L. and Allan, A.R. (1996) Redbrick University Revisited: The Autobiography of Brouce Truscot. Liverpool University Press.

[8] Kennedy, D. (1997) Academic Duty. Harvard University Press.

[9] Benson, L. and Harkavy, I. (2000) Higher Education’s Third Revolution: The Emergence of the Democratic Cosmopolitan Civic University. Cityscape, 5, 47-57.

[10] Stoke, D.E. (1997) Pasteur’s Quadrant: Basic Science and Technological Innovation. Brookings Institution Press.

[11] Goddard, J. and Vallance, P. (2011) The Civic University and the Leadership of Place. Centre for Urban and Regional Development Studies (CURDS), Newcastle University, UK. 